\title{
Single portal pressure measurement predicts survival in cirrhotic patients with recent bleeding
}

D Patch, A Armonis, C Sabin, K Christopoulou, L Greenslade, A McCormick, R Dick, A K Burroughs
Liver Transplantation and Hepatobiliary Medicine, The Royal Free Hospital, London, UK

D Patch

A Armonis

K Christopoulou

L Greenslade

A McCormick

R Dick

A K Burroughs

Department of Primary Care and

Population Sciences, The Royal Free

Hospital, London, UK

C Sabin

Correspondence to: Dr A K Burroughs,

Consultant Physician and

Hepatologist, Liver

Transplantation and

Hepatobiliary Medicine,

Royal Free Hospital, Pond

Street, London NW3 2QG,

UK.

Accepted for publication 2 September 1998

\begin{abstract}
Background-Height of portal pressure correlates with severity of alcoholic cirrhosis. Portal pressure indices are not however used routinely as predictors of survival.

Aims-To examine the clinical value of a single portal pressure measurement in predicting outcome in cirrhotic patients who have bled.

Methods-A series of 105 cirrhotic patients who consecutively underwent hepatic venous pressure measurement were investigated. The main cause of cirrhosis was alcoholic $(64.8 \%)$ and prior to admission all patients had bled from varices.

Results-During the follow up period (median 566 days, range 10-2555), 33 patients died, and 54 developed variceal haemorrhage. Applying Cox regression analysis, hepatic venous pressure gradient, bilirubin, prothrombin time, ascites, and previous long term endoscopic treatment were the only statistically independent predictors of survival, irrespective of cirrhotic aetiology. The predictive value of the pressure gradient was much higher if the measurement was taken within the first or the second week from the bleeding and there was no association after 15 days. A hepatic venous pressure gradient of at least $16 \mathrm{~mm} \mathrm{Hg}$ appeared to identify patients with a greatly increased risk of dying.

Conclusions-Indirectly measured portal pressure is an independent predictor of survival in patients with both alcoholic and non-alcoholic cirrhosis. In patients with a previous variceal bleeding episode this predictive value seems to be better if the measurement is taken within the first two weeks from the bleeding episode. A greater use of this technique is recommended for the prognostic assessment and management of patients with chronic liver disease.

(Gut 1999;44:264-269)
\end{abstract}

Keywords: chronic liver disease; alcoholic cirrhosis; portal pressure

The classification of Child and Turcotte ${ }^{1}$ or its modification by $\mathrm{Pugh}^{2}$ is currently the most commonly used prognostic test for assessment of survival in cirrhotic patients. These classifications are based on clinical and biochemical criteria and carry a sensitivity and specificity of approximately $80 \%$ when used in prognostic score modelling. ${ }^{3}$

However, in recent years greater accuracy of assessment of prognosis has become necessary with the increasing use of liver transplantation. The quantitative liver function tests have been evaluated by many studies but these tend to be complicated to perform, and have not conclusively been proved to be better than the ChildPugh classification. ${ }^{4}$ Thus other accurate and simple prognostic markers are required.

Portal pressure has been shown to be closely correlated with the severity of cirrhosis, as assessed by liver biopsy ${ }^{5}$ or by the Child-Pugh classification. $^{7}$ Thus conceptually one would imagine portal pressures to be predictive of survival. We have recently reviewed the trials and studies with respect to portal pressure and prognosis, and concluded that the evidence available suggested reasonable predictive value, ${ }^{8}$ although in routine clinical practice, portal pressure measurements are not used to aid outcome prediction. It was clear however that these studies are heterogeneous, particularly with respect to timing of wedge pressure measurement in relation to bleeding.

This study was therefore performed in order to examine the clinical value of indirect portal pressure measurement with respect to four principal issues: (1) Does portal pressure predict death and bleeding? (2) Is this true for all aetiologies of cirrhosis? (3) Is there an ideal time to perform this measurement, in relation to a bleeding episode (as most assessments of portal pressure are currently taken in patients who have bled)? (4) In the same way that there is a threshold value for bleeding, is there also a threshold value for mortality, which therefore identifies a higher risk group?

\section{Patients and methods}

STUDY POPULATION

A series of 170 patients with cirrhosis were investigated. These patients consecutively underwent hepatic venography and pressure measurement at the Royal Free Hospital from March 1988 until December 1995. A total of 65 patients was excluded from the final analysis for the following reasons: absence of varices at the time of hepatic venous pressure measurement (16 patients); previous surgery for variceal bleeding (five patients); measurements

Abbreviations used in this paper: FHVP, free hepatic venous pressure; HVPG, hepatic venous pressure gradient; WHVP, wedge hepatic venous pressure; TIPS, transjugular intrahepatic portosystemic shunt; PSE, portosystemic encephalopathy. 
Table 1 Clinical, biochemical, and endoscopic data at entry into the study

\begin{tabular}{ll}
\hline Variable & Number \\
\hline Aetiology of cirrhosis & \\
Alcoholic & 68 \\
Primary biliary cirrhosis & 10 \\
Primary sclerosing cholangitis & 5 \\
Post-hepatitis & 9 \\
Autoimmune & 2 \\
Cryptogenic & 8 \\
Other & 3 \\
Child-Pugh classification (A/B/C) & $28 / 41 / 36$ \\
Child-Pugh score & $8(5-5)$ \\
Previous long term treatment & \\
Drugs & 11 \\
Endoscopic & 25 \\
Treatment of acute bleeding & \\
Medical & 51 \\
Sclerotherapy & 54 \\
Source of acute bleeding & \\
Oesophageal varices & 93 \\
Gastric varcies & 6 \\
Portal hypertensive gastropathy & 6 \\
Oesophageal varices (small/medium/large) & $17 / 38 / 50$ \\
Gastric varices & 14 \\
Portal gastropathy & 52 \\
Secondary treatment & 66 \\
Medical & $39 / 13 / 3$ \\
Sclerotherapy & \\
Biochemical values (mean (SD)) & \\
Bilirubin (mmol/1) & $53.9(57.6)$ \\
Albumin (g/l) & $38.4(29.4)$ \\
Prothrombin time (seconds) & $18.1(10.4)$ \\
Ascites (none/mild/moderate to severe) & $62 / 94$ \\
Encephalopathy (none/mild/moderate to severe) & $89 / 1$ \\
\hline & \\
\hline & \\
&
\end{tabular}

were taken in order to examine TIPS (transjugular intrahepatic portosystemic shunt) patency (14 patients); non-cirrhotic portal hypertension (eight patients), and incomplete data on survival or incomplete medical records (22 patients). Thus 105 patients (68 men, 37 women) who had had a portal hypertensive related bleed were finally included in the study, with the diagnosis of cirrhosis confirmed by clinical, biochemical, or histological means. Median age was 51 years (range 21-79) and the principal cause of cirrhosis was alcoholic $(\mathrm{n}=68,64.8 \%)$. The distribution according to the Child-Pugh classification was: A, 28 $(26.7 \%)$; B, 41 (39.0\%); and C, $36(34.3 \%)$. Prior to admission 36 patients were already on long term medical $(n=11)$ or endoscopic (sclerotherapy or ligation, $n=25$ ) treatment for the prevention of rebleeding following a previous bleed. Only one patient was on $\beta$ blocker primary prophylaxis.

Emergency endoscopic treatment (sclerotherapy or banding) was used in 54 of the 105 patients admitted with acute variceal haemorrhage; the remaining 51 were managed by medical treatment (fluid resuscitation, and/or vasoactive drugs, and/or balloon tamponade). Sixty six of the 105 patients admitted with bleeding commenced $\beta$ blocker therapy. Sclerotherapy and surgery were used when this initial approach had failed, or when there were contraindications to the use of drugs. Table 1 presents the detailed clinical and biochemical data of the patients.

HEPATIC VEIN CATHETERISATION

The measurement of portal pressure was done within a median of 11 days (range 0-372) from the acute bleeding episode. All patients at the time of measurement were haemodynamically stable, not septic, and not bleeding. One patient was catheterised on the day of admission following a non-significant variceal bleed. Thirty five patients had wedge pressures measured more than two weeks following their bleed. This was principally for logistical reasons-patients were fit enough to be discharged before the measurement could be performed, and therefore secondary preventative therapy was commenced before a baseline hepatic venous pressure gradient (HVPG) was measured. For those patients on drug therapy for the prevention of rebleeding, medication was continued on the day of HVPG measurement (17/31).

The hepatic vein catheterisation was performed in the supine position under local anaesthesia following a six hour fast. A $7 \mathrm{Fr}$ balloon catheter was inserted into the right femoral vein though an $8 \mathrm{Fr}$ introducer set (Cordis Corp., Miami, Florida, USA). This torque controlled catheter was directed into the hepatic vein under fluoroscopic control and pressure measurements were taken in the wedged (WHVP) and free (FHVP) position by inflating and deflating the balloon in the tip of the catheter. Measurements were taken three times and the HVPG was calculated as the mean of the three pressure gradients-the difference between WHVP and FHVP.

\section{VARIABLES EVALUATED}

Sixteen variables (11 qualitative and five quantitative) collected at the time of the portal pressure measurement were examined. The qualitative variables were: sex, aetiology of cirrhosis (alcoholic or non-alcoholic), information about previous variceal bleeding episodes and current long term treatment for the prevention of first bleeding or rebleeding, source of the acute bleeding, size of varices and presence of portal gastropathy or gastric varices, type of treatment of the acute bleeding episode immediately prior to the measurement, degree of portosystemic encephalopathy, and the degree of ascites. The quantitative variables were age, bilirubin, albumin, prothrombin time, and HVPG.

\section{STATISTICAL ANALYSIS}

The relation between HVPG and the previous bleeding episodes, size of oesophageal varices (according to the NIEC classification ${ }^{9}$ ) and the presence of gastric varices or portal gastropathy were studied using Wilcoxon or Kruskal-Wallis tests, where appropriate.

Time to first or next bleeding and time to death were analysed from the date of entry to the study using Kaplan-Meier methods. Differences between survival curves using two HVPG values were analysed using the log rank test $-17 \mathrm{~mm} \mathrm{Hg}$ (our median value) and 16 $\mathrm{mm} \mathrm{Hg}$, a value previously suggested to provide prognostic significance..$^{10}$

Time of entry to the study was at the time of the HVPG measurement, and the clinical and biochemical values were established at this point. Univariate and multivariate relations between survival or rebleeding and variables of interest were examined using Cox proportional hazards models. Patients were included in the 
Table 2 Factors associated with survival-univariate model

\begin{tabular}{|c|c|c|c|c|c|c|}
\hline Variable & $\begin{array}{l}\text { Survivors } \\
(n=72)\end{array}$ & $\begin{array}{l}\text { Non-survivors } \\
(n=33)\end{array}$ & $\begin{array}{l}\text { Relative } \\
\text { hazard }\end{array}$ & $\begin{array}{l}\text { Lower } \\
95 \% \text { CI }\end{array}$ & $\begin{array}{l}\text { Upper } \\
95 \% C I\end{array}$ & p Value \\
\hline Median age (years) & $51(21-73)$ & $53(31-79)$ & 1.01 & 0.98 & 1.04 & 0.62 \\
\hline \multicolumn{7}{|l|}{ Sex } \\
\hline Male & $46(64 \%)$ & $22(67 \%)$ & 1 & 0 & 0 & 0 \\
\hline Female & $26(36 \%)$ & $11(33 \%)$ & 0.93 & 0.45 & 1.94 & 0.86 \\
\hline Alcoholic cirrhosis & $42(58 \%)$ & $26(79 \%)$ & 0.47 & 0.20 & 1.09 & 0.08 \\
\hline \multicolumn{7}{|l|}{ Current bleeding episode } \\
\hline Non-active & & & 1 & 0 & 0 & 0 \\
\hline Active & $21(29 \%)$ & $13(39 \%)$ & 1.08 & 0.52 & 2.21 & 0.84 \\
\hline \multicolumn{7}{|c|}{ Previous long term treatment } \\
\hline Drug & $8(11 \%)$ & $3(9 \%)$ & 0.89 & 0.27 & 2.95 & 0.85 \\
\hline Endoscopic & $14(19 \%)$ & $11(33 \%)$ & 1.98 & 0.95 & 4.11 & 0.07 \\
\hline \multicolumn{7}{|l|}{ Oesophageal varices } \\
\hline Large & $35(49 \%)$ & $15(45 \%)$ & 1.30 & 0.47 & 3.60 & 0.61 \\
\hline Medium & $25(35 \%)$ & $13(39 \%)$ & 1.01 & 0.36 & 2.88 & 0.98 \\
\hline Small & $12(17 \%)$ & $5(15 \%)$ & 1 & 0 & 0 & 0 \\
\hline \multicolumn{7}{|l|}{ Portal hypertensive } \\
\hline gastropathy & $31(43 \%)$ & $21(64 \%)$ & 2.04 & 0.99 & 4.17 & 0.05 \\
\hline Gastric varices & $11(11 \%)$ & $3(9 \%)$ & 0.92 & 0.28 & 3.02 & 0.89 \\
\hline \multicolumn{7}{|l|}{ Previous bleeding from } \\
\hline oesophageal varices & $60(83 \%)$ & $30(91 \%)$ & 1.83 & 0.56 & 6.00 & 0.32 \\
\hline \multicolumn{7}{|c|}{ Acute treatment of variceal bleeding } \\
\hline Medical & $38(53 \%)$ & $13(39 \%)$ & 1 & 0 & 0 & 0 \\
\hline Sclerotherapy & $34(47 \%)$ & $20(61 \%)$ & 1.69 & 0.82 & 3.47 & 0.15 \\
\hline Bilirubin (per 10 units) ${ }^{\star}$ & $43.6(39)$ & $76.5(81)$ & 1.09 & 1.04 & 1.14 & 0.0001 \\
\hline Prothrombin time $(\mathrm{s})^{\star}$ & $16.5(3.0)$ & $21.4(17.7)$ & 1.03 & 1.02 & 1.05 & 0.0004 \\
\hline Albumin $(\mathrm{g} / \mathrm{l})^{\star}$ & $39.5(33.3)$ & $35.9(18.8)$ & 0.95 & 0.91 & 0.99 & 0.03 \\
\hline PSE & $66 / 6 / 0$ & $23 / 7 / 3$ & 2.90 & 1.62 & 5.19 & 0.0003 \\
\hline Ascites & $52 / 5 / 15$ & $10 / 4 / 19$ & 1.97 & 1.44 & 2.68 & 0.0001 \\
\hline Median Child-Pugh score & $7(5-12)$ & $10(5-15)$ & 1.53 & 1.29 & 1.82 & 0.0001 \\
\hline Median HVPG & $16(7-29)$ & $18(10-44)$ & 1.12 & 1.04 & 1.21 & 0.002 \\
\hline
\end{tabular}

^Expressed as mean (SD).

CI, confidence interval; PSE, portosystemic encephalopathy.

risk set from the time of entry to the study. For progression to rebleeding, patient follow up was right censored at the time of death if they had not bled. For all analyses, follow up was additionally right censored at the end of the study period. All variables were initially tested for significance in univariate models. Those which were univariately associated with either rebleeding or survival at a level of $\mathrm{p}<0.1$ were entered into a multivariate model using a stepwise procedure in PROC PREG in SAS (SAS Institute Inc., Cory, North Carolina, USA). ${ }^{11}$

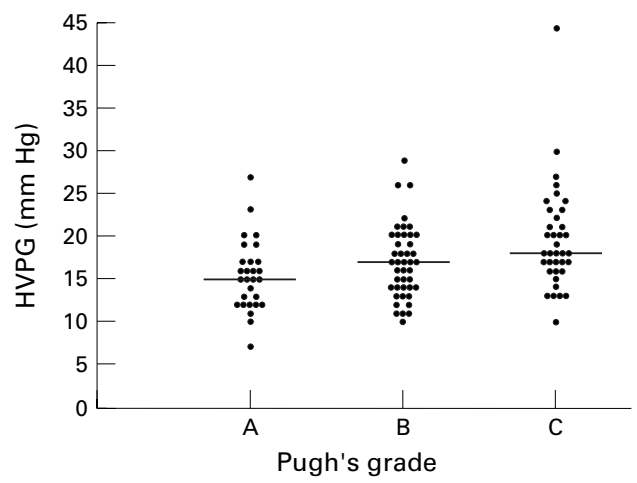

Figure 1 Hepatic venous pressure gradient versus Child-Pugh grade.

Table 3 Factors associated with survival-multivariate model

\begin{tabular}{lllll}
\hline Variable & $\begin{array}{l}\text { Relative } \\
\text { hazard }\end{array}$ & $\begin{array}{l}\text { Lower } \\
95 \% \text { CI }\end{array}$ & $\begin{array}{l}\text { Upper } \\
95 \% \text { CI }\end{array}$ & p Value \\
\hline HVPG & 1.11 & 1.02 & 1.21 & 0.01 \\
Prothrombin time & 1.04 & 1.02 & 1.07 & 0.0004 \\
Bilirubin (per 10 units) & 1.05 & 1.00 & 1.10 & 0.04 \\
Ascites & 2.18 & 1.54 & 3.10 & 0.0001 \\
Previous long term endoscopic treatment & 3.50 & 1.57 & 7.83 & 0.002 \\
\hline
\end{tabular}

CI, confidence interval.

\section{Results}

At the time of inclusion the median value of HVPG was $17 \mathrm{~mm} \mathrm{Hg}$ (range 7-44). The median values of WHVP and FHVP were 23 $\mathrm{mm} \mathrm{Hg}$ (range 10-52) and $7 \mathrm{~mm} \mathrm{Hg}(0-21)$ respectively. Height of HVPG was found to correlate significantly with the severity of cirrhosis as assessed by the Child-Pugh classification ( $p=0.005$, fig 1 ). In contrast HVPG did not correlate with either the size of oesophageal varices or the presence of portal gastropathy or gastric varices. This lack of relation persisted when patients who had previous sclerotherapy were excluded.

HVPG was not significantly different in patients who had previously bled from oesophageal varices (median $17 \mathrm{~mm} \mathrm{Hg}$, range 7-44) and those who had bled from other sites (median19 $\mathrm{mm} \mathrm{Hg}$, range 12-26; $\mathrm{p}=0.34$ ). Eight patients had HVPG levels less than 12 $\mathrm{mm} \mathrm{Hg}$ (three alcoholics, three with primary biliary cirrhosis, and two with cryptogenic cirrhosis). Only one of the alcoholic patients who had bled from varices with an HVPG less than $12 \mathrm{~mm} \mathrm{Hg}$ had their wedge pressure measurement performed greater than two weeks following their bleed (not on $\beta$ blockers). In the remaining two alcoholic patients, portal vein thrombosis was specifically excluded.

\section{FACTORS PREDICTING DEATH}

Death occurred in 33 patients (31.4\%) during the follow up period (median 566 days, range 10-2555). Death was related to bleeding in 21 patients, of whom 10 died within six weeks. Liver failure accounted for 11 deaths. Only one patient in this series died of a non-liver related cause (bladder carcinoma). Six patients were 


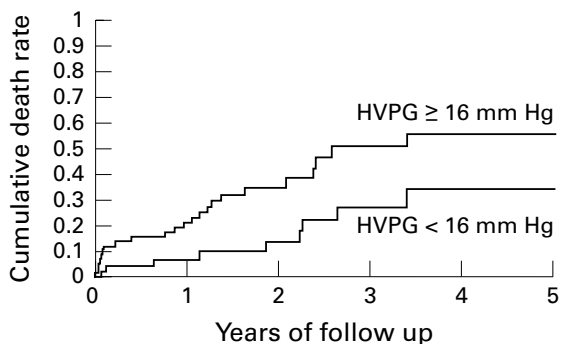

Number at risk

$\begin{array}{lllllll}\mathrm{HVPG}<16 & 46 & 33 & 22 & 11 & 9 & 5 \\ \mathrm{HVPG} \geq 16 & 59 & 41 & 20 & 10 & 5 & 3\end{array}$

Figure 2 Cumulative death rate in relation to free hepatic venous pressure gradient (HVPG).

transplanted during this time period, and were censored at this time point.

Univariate analysis showed that factors associated with lower probability of survival were: alcoholic cirrhosis, previous long term endoscopic treatment, high bilirubin, presence of portal hypertensive gastropathy, high prothrombin, low albumin, presence of ascites, encephalopathy, and high values of HVPG (table 2$)$. Of these, only HVPG $(\mathrm{p}=0.01)$, previous long term endoscopic treatment $(\mathrm{p}=0.002)$, prothrombin time $(\mathrm{p}=0.0004)$, bilirubin $(p=0.04)$, and ascites $(p=0.0001)$ were found to have independent prognostic value in the multivariate analysis. Table 3 presents the statistical parameters. If patients from the study who had previously bled were excluded, the trend of HVPG to predict survival did not reach significance $(p=0.09)$. It is likely that this is a type 2 error as a consequence of removing over a third of the patients.

Of the 105 patients with a previous variceal bleeding episode, 22 patients $(21 \%)$ had the HVPG measurement within the first week and
48 patients $(45.7 \%)$ within the second week of bleeding. In the remaining 35 patients $(33.3 \%)$ the catheterisation was performed after the sixteenth day following the haemorrhage. Dividing the patients into these three groups, the predictive value of the HVPG was found to be much higher if the measurement was taken within the first $(p=0.03)$ or the second $(p=0.001)$ week following the haemorrhage than that taken later $(p=0.92)$. If patients on medical therapy were removed from the group who had their HVPG measurement after two weeks (as these patients may have a pharmacologically reduced portal pressure), the predictive value of the wedge pressure was still not significant (relative hazard $=1.11, \mathrm{p}=0.26$ ).

During the observation period, 23 of the 58 patients $(39.7 \%)$ who had a gradient greater or equal to the median value of $17 \mathrm{~mm} \mathrm{Hg}$ died. The corresponding number for the 47 patients with HVPG less than $17 \mathrm{~mm} \mathrm{Hg}$ was 10 $(21.3 \%)$. There was a significant difference in the cumulative probability of survival between these two groups $(p=0.05)$. Dividing the patients at the level of $16 \mathrm{~mm} \mathrm{Hg}$, the cumulative probability of death was found to be significantly higher in the 59 patients with an HVPG equal or greater than $16 \mathrm{~mm} \mathrm{Hg}$, of whom 24 died during follow up $(\mathrm{p}=0.02$, fig 2$)$.

\section{FACTORS PREDICTING HAEMORRHAGE}

During the observation period, 54 patients experienced at least one episode of further upper gastrointestinal bleeding. Causes of bleeding were oesophageal varices in 49 patients, gastric varices in three, portal hypertensive gastropathy in one, and duodenal erosions in one. Fourteen of these patients subsequently had a radiological or surgical portosystemic shunt.

According to univariate analysis (table 4), previous long term endoscopic treatment,

Table 4 Factors associated with rebleeding-univariate model

\begin{tabular}{|c|c|c|c|c|c|c|}
\hline Variable & $\begin{array}{l}\text { No rebleeding } \\
(n=51)\end{array}$ & $\begin{array}{l}\text { Rebleeding } \\
(n=54)\end{array}$ & $\begin{array}{l}\text { Relative } \\
\text { hazard }\end{array}$ & $\begin{array}{l}\text { Lower } \\
95 \% \text { CI }\end{array}$ & $\begin{array}{l}\text { Upper } \\
95 \% C I\end{array}$ & $p$ Value \\
\hline Median age (years) & $53(25-79)$ & $51(21-77)$ & 0.98 & 0.96 & 1.00 & 0.11 \\
\hline \multicolumn{7}{|l|}{ Sex } \\
\hline Male & $33(65 \%)$ & $35(65 \%)$ & 1 & 0 & 0 & 0 \\
\hline Female & $18(35 \%)$ & $19(35 \%)$ & 0.97 & 0.55 & 1.70 & 0.91 \\
\hline Alcoholic cirrhosis & $34(67 \%)$ & $34(63 \%)$ & 1.15 & 0.66 & 2.02 & 0.63 \\
\hline \multicolumn{7}{|l|}{ Current variceal bleeding } \\
\hline Non-active & $38(75 \%)$ & $33(61 \%)$ & 1 & 0 & 0 & 0 \\
\hline Active & $13(26 \%)$ & $21(39 \%)$ & 1.34 & 0.76 & 2.33 & 0.31 \\
\hline \multicolumn{7}{|l|}{ Previous long term treatment } \\
\hline Drug & $6(12 \%)$ & $5(9 \%)$ & 0.99 & 0.39 & 2.50 & 0.98 \\
\hline Endoscopic & $10(20 \%)$ & $15(28 \%)$ & 1.76 & 0.96 & 3.23 & 0.07 \\
\hline \multicolumn{7}{|l|}{ Oesophageal varices } \\
\hline Large & $22(43 \%)$ & $28(52 \%)$ & 2.02 & 0.83 & 4.92 & 0.12 \\
\hline Medium & $18(35 \%)$ & $20(37 \%)$ & 1.56 & 0.62 & 3.92 & 0.35 \\
\hline Small & $11(22 \%)$ & $6(11 \%)$ & 1 & 0 & 0 & 0 \\
\hline Portal hypertensive gastropathy & $23(45 \%)$ & $29(54 \%)$ & 1.06 & 0.96 & 1.17 & 0.27 \\
\hline Gastric varices & $4(8 \%)$ & $10(19 \%)$ & 1.92 & 0.96 & 3.84 & 0.07 \\
\hline \multicolumn{7}{|l|}{ Source of previous bleeding } \\
\hline Oesophageal varices & $45(88 \%)$ & $45(83 \%)$ & 0.84 & 0.41 & 1.73 & 0.64 \\
\hline \multicolumn{7}{|c|}{ Treatment of the previous acute bleeding episode } \\
\hline Medical & $28(55 \%)$ & $23(43 \%)$ & 1 & 0 & 0 & 0 \\
\hline Sclerotherapy & $23(45 \%)$ & $31(57 \%)$ & 1.69 & 0.97 & 2.93 & 0.06 \\
\hline Bilirubin (per 10 units) ${ }^{\star}$ & $47.5(38.9)$ & $60.0(70.7)$ & 1.01 & 0.97 & 1.05 & 0.67 \\
\hline Prothrombin time $e^{\star}$ & $16.7(2.7)$ & $19.4(14.1)$ & 1.05 & 1.02 & 1.08 & 0.0007 \\
\hline Albumin $\star$ & $40.3(39.4)$ & $36.5(15.2)$ & 0.98 & 0.96 & 1.01 & 0.14 \\
\hline PSE & $44 / 6 / 1$ & $45 / 7 / 2$ & 1.10 & 0.57 & 2.13 & 0.77 \\
\hline Ascites & $33 / 6 / 12$ & 29/3/22 & 1.17 & 0.92 & 1.51 & 0.21 \\
\hline Median Child-Pugh score & $8(5-14)$ & $8.5(5-15)$ & 1.06 & 0.95 & 1.18 & 0.29 \\
\hline Median HVPG & $17(7-44)$ & $17(10-27)$ & 1.01 & 0.95 & 1.08 & 0.71 \\
\hline
\end{tabular}

^Expressed as mean (SD).

CI, confidence interval; PSE, portosystemic encephalopathy. 

Table 5 Factors associated with rebleeding-multivariate
Cox model

\begin{tabular}{lllll}
\hline Variable & $\begin{array}{l}\text { Relative } \\
\text { hazard }\end{array}$ & $\begin{array}{l}\text { Lower } \\
95 \% \text { CI }\end{array}$ & $\begin{array}{l}\text { Upper } \\
95 \% \text { CI }\end{array}$ & p Value \\
\hline $\begin{array}{l}\text { Previous long term } \\
\text { endoscopic treatment }\end{array}$ & 1.88 & 1.02 & 3.47 & 0.04 \\
$\begin{array}{l}\text { Prothrombin time } \\
1.05\end{array}$ & 1.02 & 1.08 & 0.004 \\
\hline
\end{tabular}

presence of gastric varices, acute bleeding requiring sclerotherapy (oozing or spurting varix at the time of endoscopy), and prothrombin time were found to be associated with an increased risk of rebleeding. Multivariate analysis identified previous long term endoscopic treatment $(\mathrm{p}=0.04)$, and prothrombin time $(\mathrm{p}=0.004)$ as independent variables predicting rebleeding (table 5).

HVPG was not found to be associated with the risk of rebleeding, when stratified for the HVPG values of either 16 or $17 \mathrm{~mm} \mathrm{Hg}$ in the Kaplan-Meier analysis $(p=0.50$ and $p=0.60$ respectively), or when included as a continuous variable in the Cox model $(p=0.71)$. In addition, no relation was observed when patients who had an HVPG measurement performed after two weeks were excluded $(p=0.60)$.

The presence of previous endoscopic therapy in both multivariate analyses as a significant factor was analysed further. Patients who had bled before were grouped together, and their treatment modality was excluded from the univariate analysis. Perhaps surprisingly, previous bleeding was not identified as a significant factor in the subsequent univariate analysis, while the multivariate analysis identified the same significant factors-prothrombin time, bilirubin, ascites, and HVPG, with respect to survival; and prothrombin time with respect to rebleeding. Thus the presence of previous endoscopic therapy as a significant factor reflected previous bleeding, but was also likely to reflect treatment allocation bias. Patients who were intolerant of $\beta$ blockers (because of cardiopulmonary disease) and who had already failed pharmacotherapy were allocated to sclerotherapy, and thus had a greater risk of rebleeding and death at entry to the study.

\section{Discussion}

The results of this study suggest that the single measurement of portal pressure as estimated by hepatic vein catheterisation provides useful prognostic information in cirrhotic patients, in addition to that obtained from conventional investigation. In our particular group of patients (all of whom had experienced variceal bleeding), HVPG measurement was an independently associated variable with death if performed within two weeks of a variceal bleed. In addition, previous long term endoscopic treatment, bilirubin, prothrombin time, and ascites were also found to be significant and independent determinants of survival.

Our study differs from those published previously in a number of ways. Our patient group was heterogeneous in terms of aetiology, and was not confined to alcoholic cirrhosis. In this respect, recent data suggest that HVPG measurement reliably reflects portal pressure in posthepatitic cirrhosis, ${ }^{12}{ }^{13}$ as well as alcoholic liver disease. There does however remain concern that in diseases with a presinusoidal element to their portal hypertension (for example, primary biliary cirrhosis, primary sclerosing cholangitis), HVPG measurement may underestimate the true portal pressure. Nonetheless, in this multivariate analysis, there was no difference in the predictive value in patients with an alcoholic compared with a non-alcoholic aetiology.

In addition, this study examined the role of a single HVPG measurement, in contrast to the study of Vorobioff et $a l,{ }^{14}$ which recently showed the prognostic value of sequential HVPG measurement in 30 patients with alcoholic cirrhosis. HVPG measurement at 10 months was shown to have the best prognostic and independent value in predicting survival and bleeding along with variceal size, the latter being predictive at baseline and follow up. While no "threshold" pressure value was proposed, cumulative probability of survival was significantly higher for patients in whom the HVPG decreased by at least $15 \%$ at the first follow up. In this study of patients with alcoholic cirrhosis, HVPG reduction predominantly reflected abstinence, concomitantly associated with clinical and endoscopic improvement. However, in routine clinical practice, it is not practical to perform sequential wedge pressure measurements on patients outside of specialist centres, particularly if they have not bled. There is therefore a need for a "single shot" assessment of prognosis. For this to be effective, one needs threshold indices, which signify a worse prognosis, and which ultimately identify patients in whom one may intervene at an earlier stage with transplantation, in the same way that there is a proposed threshold for variceal bleeding. A priori, we chose to examine our median value $(17 \mathrm{~mm} \mathrm{Hg})$ and the threshold value of $16 \mathrm{~mm} \mathrm{Hg}$, proposed by Merkel et al in 1992. ${ }^{10}$ His group followed up 129 cirrhotics, most of them alcoholic (71\%) for a median period of 45 months and showed that the cumulative probability of survival was significantly higher in patients with an HVPG lower than $16 \mathrm{~mm} \mathrm{Hg}$. Furthermore, Cox's regression analysis showed that previous variceal bleeding, Pugh score, indocyanine green clearance, and HVPG were all significant independent predictors of survival. Further evidence that there may be a "threshold" value comes from the data of Gluud et $a l,{ }^{15}$ who found that HVPG values greater than $15 \mathrm{~mm}$ $\mathrm{Hg}$ were associated with a significantly increased probability of death. A publication in abstract by Barret and colleagues ${ }^{16}$ examined their median HVPG of $17.5 \mathrm{~mm} \mathrm{Hg}$ in 101 patients who had not bled, and also found it to be predictive of survival. Our study identified an HVPG of $16 \mathrm{~mm} \mathrm{Hg}$ as an index for survival, confirming the data from these previous studies.

The timing of the HVPG measurement to provide the best prognostic value remains uncertain. We found that HVPG measurement greater than two weeks after a bleed was not predictive of death. Villanueva et al found the 
HVPG measurement at three months, in a group that had bled, to be the best independent predictor of mortality, along with Pugh's score and rebleeding. ${ }^{17}$ As in the study by Vorobioff $e t$ $a l,{ }^{14}$ this may reflect cessation of alcohol misuse, and as such may be an abstinence indicator, while a measurement taken soon after the index bleeding episode may reflect the outcome, independent of abstinence. The confounding effect of drug therapy cannot be ignored however, and $50 \%$ of the patients in the Villaneuva study were on $\beta$ blockers. It would thus seem prudent to document clearly which patients become abstinent during follow up. This issue of timing of wedge pressures remains an area of controversy, highlighted in 1986 by Vinel et $a l{ }^{18}$ who measured portal pressure 48 hours following a variceal bleed. Owing to the high mortality in their patients, they observed that any delay between occurrence of a bleeding episode and portal pressure measurement appears to select a sample of survivors with a significantly lower mean level of portal pressure than in those measured early. Indeed, the initial portal pressure measurement immediately following a variceal bleed may be a sum of very different factors when compared with a measurement taken some months later. This issue will only be resolved by further studies.

Different studies on the relation between height of portal pressure and risk of bleeding have arrived at opposite conclusions. ${ }^{1014} 20$ The present study failed to confirm a significant association between portal pressure and bleeding. While this seems intuitively surprising-one would expect patients with high portal pressure to bleed more-this result confirms the study by Lebrec et al, ${ }^{19}$ who concluded that the height of portal pressure is not related to the risk of bleeding, as no difference was noted in the HVPG values between the patients who bled and those who remained free of bleeding during a follow up period of one year. Our study did not however examine the value of repeat portal pressure measurements. Thus patients who rebled may have developed a much higher HVPG than their baseline value, as a consequence of disease progression.

No correlation was also found in the present study between HVPG and size of varices. However, it has been suggested that variceal wall tension is the major factor which will predict variceal rupture. ${ }^{21}$ Wall tension is a combination of pressure and size of varices, so in the context of bleeding large varices may bleed at lower pressures.

Our study is not without drawbacks. The analysis is retrospective, though the patients were a consecutive series. In addition, the patient group was not homogeneous in that some had bled before the index bleed. When this group was excluded, HVPG measurement no longer predicted survival, although this is probably a consequence of insufficient events for meaningful analysis, particularly as relative hazards were unchanged. Furthermore, the variation in the timing of HVPG measurement was wide, and ideally one would wish to perform a number of pressure studies on each patient over a period of time, in order to define better the relation between portal pressure and survival.

Despite these drawbacks, we have shown that indirect measurement of portal pressure may predict survival in cirrhosis, irrespective of disease aetiology. Furthermore, we have provided further evidence that $16 \mathrm{~mm} \mathrm{Hg}$ may be a threshold portal pressure for survival. One should now consider using HVPG measurement routinely in the initial investigation of cirrhotic patients, particularly as it may be performed on an outpatient basis at the time of transjugular biopsy and hepatic venous portography. Further studies should address the issue of the best timing of this measurement, and verify its prognostic utility in non-bleeders.

1 Conn HO. A peek at the Child-Turcotte classification. Hepatology 1981;1:673-6.

2 Pugh RWH, Murray-Lyon IM, Dawson JL, et al. Transection of the oesophagus for bleeding oesophageal varices. $B r$ 7 Surg 1983;60:646-9.

3 Infante C, Esnaola S, Villeneuve JP. Clinical and statistical validity of conventional prognostic factors in predicting short term survival among cirrhotics. Hepatology 1987;7: 660-4.

4 Reichen J. MEGX test in hepatology: the long-sought ultimate quantitative liver function test? $f$ Hepatol 1993;19: $4-7$.

5 Krogsgaard K, Gluud C, Henriksen JA, et al. Correlation between liver morphology and portal pressure in alcoholic liver disease. Hepatology 1984;4:699-703.

6 Picchiottii R, Mingazzini PL, Scucchi L, et al. Correlations between sinusoidal pressure and liver morphology in cirrhosis. F Hepatol 1994;20:364-9.

7 Braillon A, Cales P, Valla D, et al. Influence of the degree of liver failure on systemic and splanchnic haemodynamics liver failure on systemic and splanchnic haemodynamics
and on response to propranolol in patients with cirrhosis. and on response to propt
Gut $1986 ; 27: 1204-9$.

8 Armonis A, Patch D, Burroughs AK. Hepatic venous pressure measurement: an old test as a new prognostic marker in cirrhosis? Hepatology 1997;25:1:245-8.

9 North Italian Endoscopic Club for the Study and Treatment of Oesophageal Varices. Prediction of the first variceal haemorrhage in patients with cirrhosis of the liver and oesophageal varices. $N$ Engl f Med 1988;319:983-9.

10 Merkel C, Bolognesi M, Bellon S, et al. Prognostic usefulness of hepatic vein catheterisation in patients with cirrhosis and oesophageal varices. Gastroenterology 1992; 102:973-9.

11 SA Institute Inc. SAS/STAT users guide. Version 6. 4th edn. Cary, NC: SAS Institute Inc., 1989.

12 Lin HC, Tsai YT, Lee FY, et al. Comparison between portal vein pressure and wedged hepatic vein pressure in hepatitis vein pressure and wedged hepatic vein pressure
B-related cirrhosis. $\mathcal{F}$ Hepatol 1989;9:326-30.

13 Iwao $\mathrm{T}$, Toyonaga A, Ikegami M, et al. Wedged hepatic venous pressure reflects portal venous pressure during vasoactive drug administration in non-alcoholic cirrhosis. Dig Dis Sci 1994;39:2439-44

14 Vorobioff J, Groszmann RJ, Picabea E, et al. Prognostic value of hepatic venous pressure gradient measurements in alcoholic cirrhosis: a 10 year prospective study. Gastroenterology 1996;111:701-9.

15 Gluud C, Henriksen JH, Nielsen G, and the Copenhagen Study Group for Liver Disease. Prognostic indicators in cirrhotic men. Hepatology 1988;8:222-7.

16 Barret G, Bosch J, Garcia Tsao G, et al. Hepatic venous pressure measurement (HVPG) as a predictor of survival in pratients with cirrhosis. Hepatology 1990;12:52A.

17 Villanueva C, Balanzo J, Novella M, et al. Nadalol plus isosorbide mononitrate compared with sclerotherapy for the sorbide mononitrate compared with sclerotherapy for the
prevention of variceal bleeding. $N$ Engl f Med 1996;334: prevention
$1624-9$.

18 Vinel JP, Cassigneul J, Levade M, et al. Assessment of shortterm prognosis after variceal bleeding in patients with alcoholic cirrhosis by early measurement of portohepatic gradient. Hepatology 1996;6:116-17.

19 Lebrec D, Fleury P, Rueff B, et al. Portal hypertension, size of esophageal varices and risk of gastrointestinal bleeding in alcoholic cirrhosis. Gastroenterology 1980;79:1139-44.

20 Viola C, Bosch J, Mastai R, et al. Prognostic value of measurements of portal pressure in patients with cirrhosis [abstract]. F Hepatol 1987;5(suppl 1):S71.

21 Polio J, Groszmann RJ. Haemodynamic factors involved in the development and rupture of oesophageal varices: a the development and rupture of oesophageal varices: a
pathophysiologic approach to treatment. Semin Liver Dis 1986;6:318-31. 